\title{
Biothiol Xenon MRI Sensor Based on Thiol-Addition Reaction
}

Shengjun Yang, ${ }^{\dagger}$ Weiping Jiang, ${ }^{\dagger}$ Lili Ren, ${ }^{\dagger}$ Yaping Yuan, ${ }^{\dagger}$ Bin Zhang, ${ }^{\dagger}$ Qing Luo, ${ }^{\dagger}$ Qianni Guo, ${ }^{\dagger}$ Louis-S. Bouchard, ${ }^{\ddagger}$ Maili Liu, ${ }^{\dagger}$ and Xin Zhou $^{*, \dagger}$

${ }^{\dagger}$ Key Laboratory of Magnetic Resonance in Biological Systems, State Key Laboratory of Magnetic Resonance and Atomic and Molecular Physics, National Center for Magnetic Resonance in Wuhan, Wuhan Institute of Physics and Mathematics, Chinese Academy of Sciences, Wuhan, 430071, China

${ }^{\ddagger}$ Department of Chemistry and Biochemistry, California NanoSystems Institute, The Molecular Biology Institute, University of California, Los Angeles, California 90095, United States

*Email: xinzhou@wipm.ac.cn 


\section{Supporting Information}

\section{Contents:}

1. Characterization of cryptophane 1

2. Time dependent ${ }^{129} \mathrm{Xe}$ NMR signal of cryptophane 1 interacting with biothiols

3. Biosensor 1 in response to the low Cys concentration

4. Biosensor 1 in response to Cys in HEPES buffer with $10 \%$ DMSO

5. Absorption spectra of cryptophane 1 treated with 10 equiv of Cys

6. Biosensor 1 in response to Hcy

7. Biosensor 1 in response to GSH

8. TOF-MS spectrum of reaction product between cryptophane 1 and Cys

9. ${ }^{1} \mathrm{H}$ NMR spectral comparison between cryptophane 1 and [1-Cys] adduct

10. ${ }^{129}$ Xe NMR chemical shift comparison of cryptophane 1 , cryptophane 2 and [1-Cys] adduct

11. ${ }^{129} \mathrm{Xe}$ spectra of cryptophane 1 in the presence of various analytes

12. Sensitivity of biosensor 1

13. Biosensor 1 in response to GSH and Hcy in bovine serum solution 


\section{Characterization of cryptophane 1:}

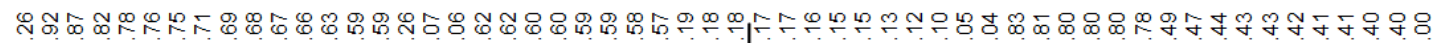

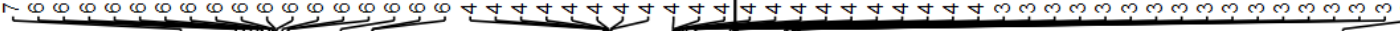

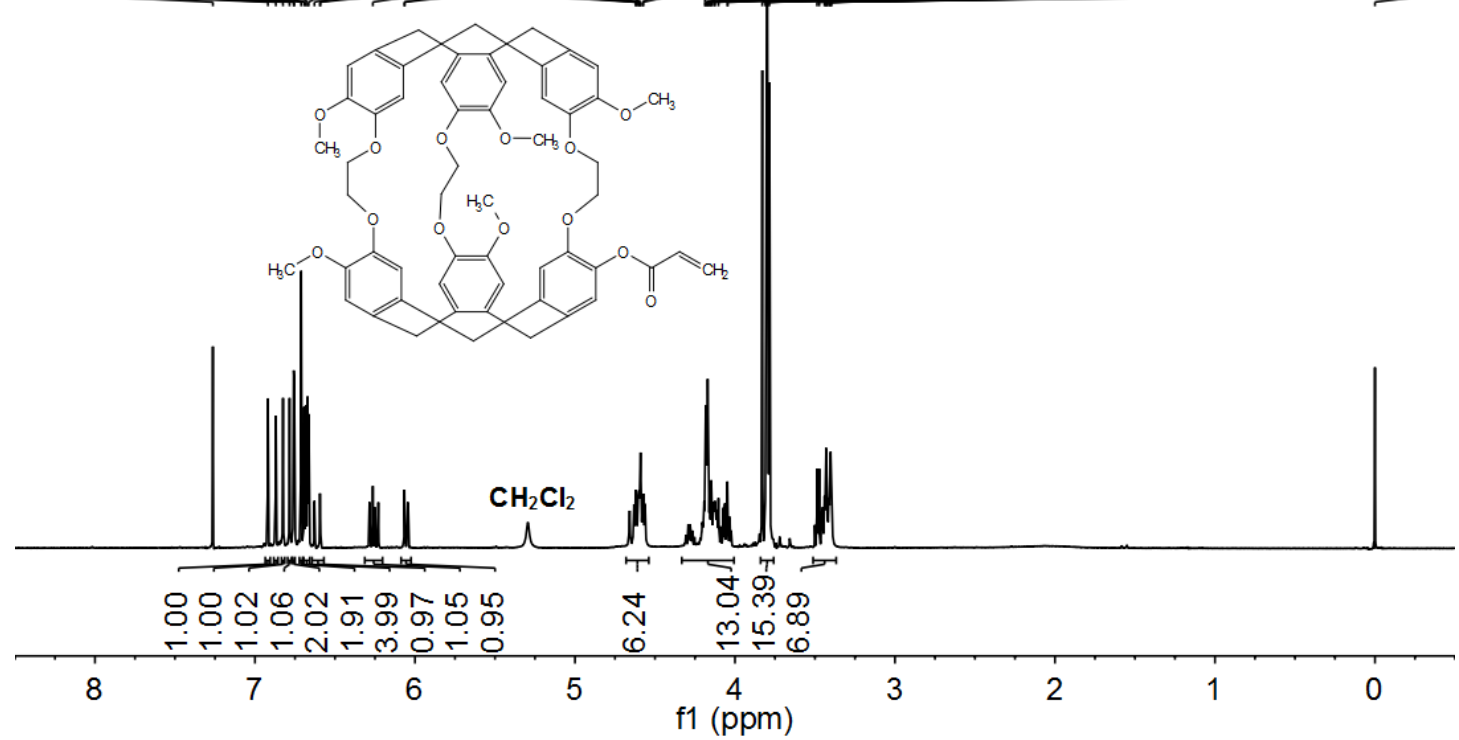

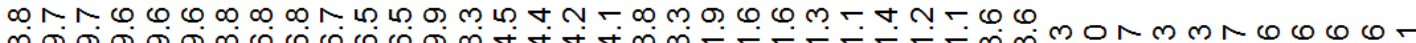

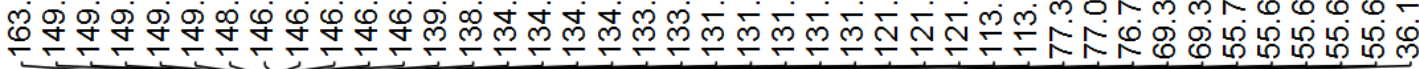
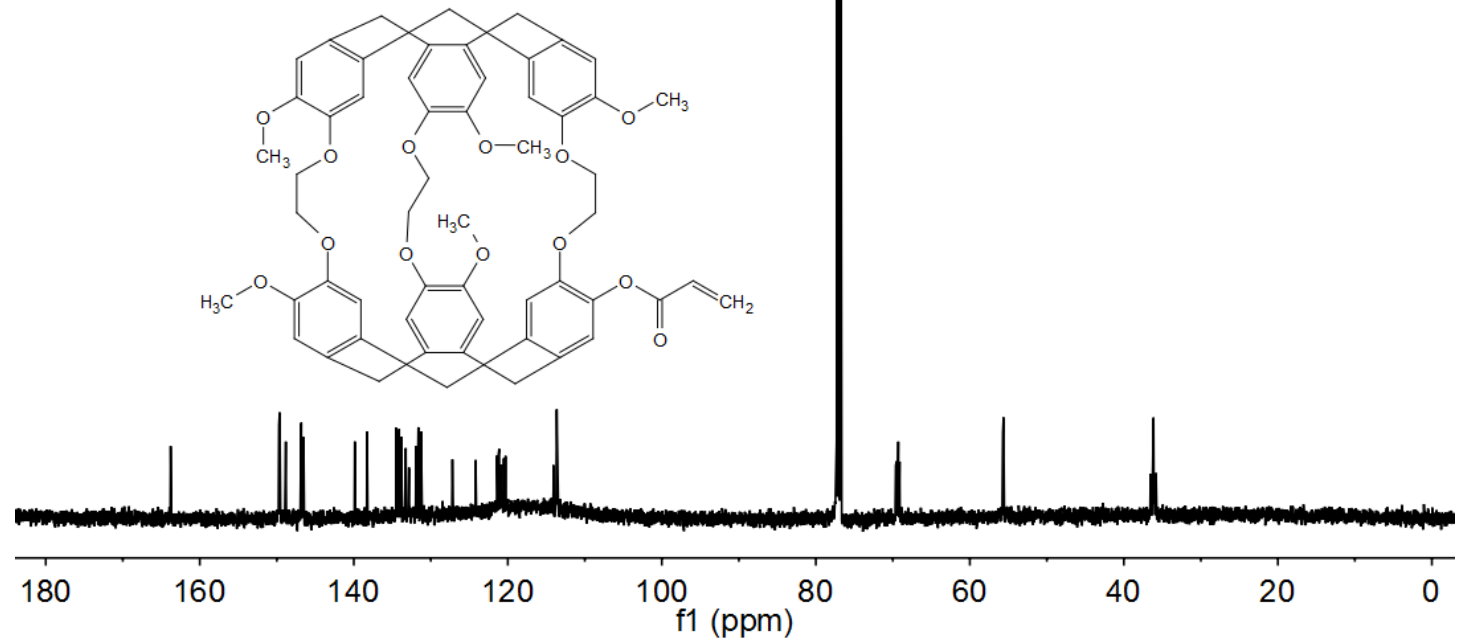

Figure S1. ${ }^{1} \mathrm{H}$ (upper) and ${ }^{13} \mathrm{C}$ (lower) NMR spectra of cryptophane 1 recorded in $\mathrm{CDCl}_{3}$. 


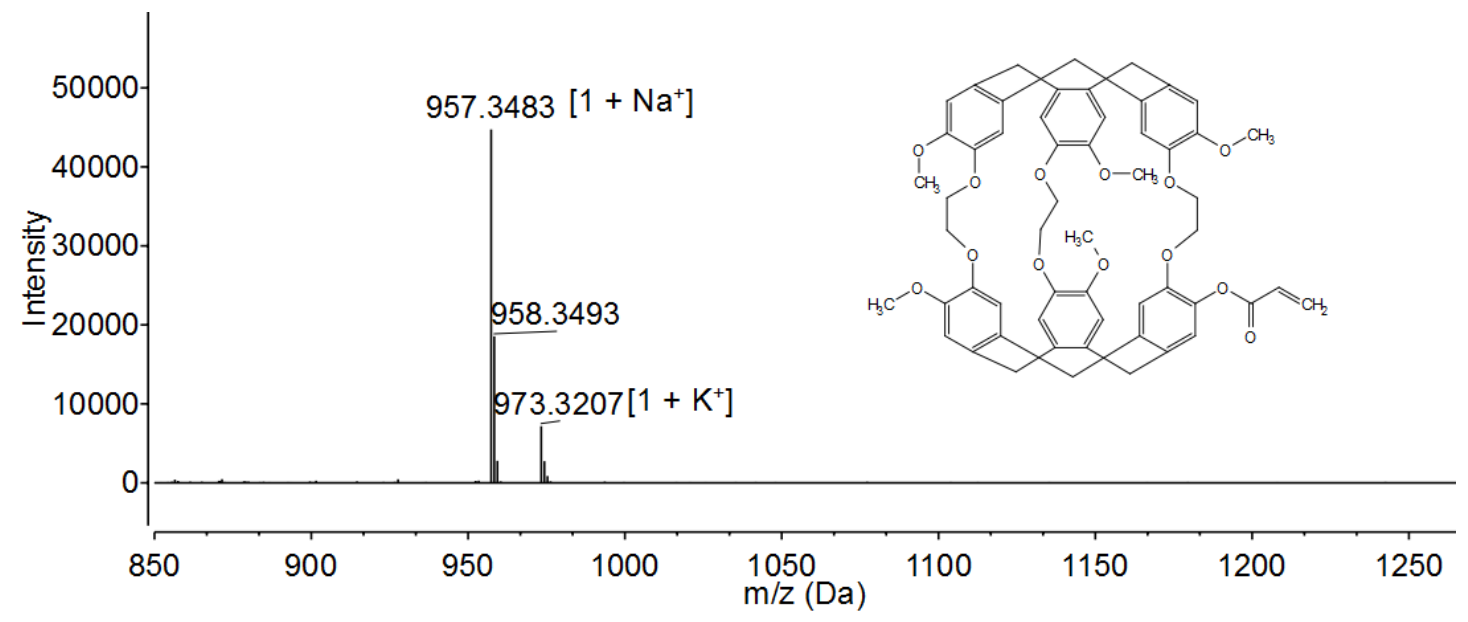

Figure S2. HR MS-ESI of cryptophane 1.

2. Time dependent ${ }^{129} \mathrm{Xe}$ NMR signal of cryptophane 1 interacting with biothiols:

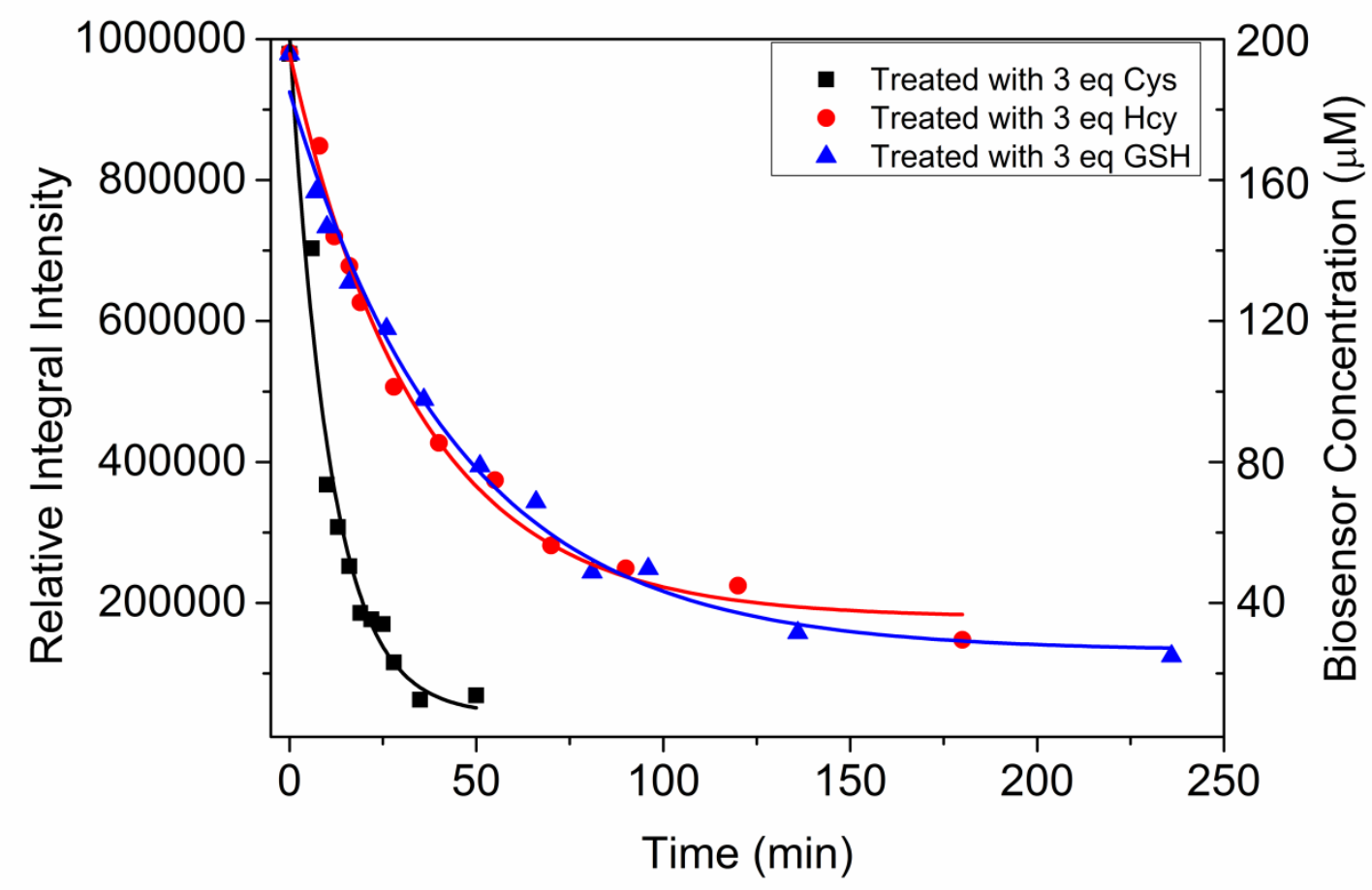

Figure S3. Time-dependent ${ }^{129} \mathrm{Xe} \mathrm{NMR} \mathrm{signal} \mathrm{intensity} \mathrm{at} \delta=76.9 \mathrm{ppm}$ (left) and the corresponding concentration change (right) of cryptophane $1(200 \mu \mathrm{M})$ after treated with 3 equiv Cys $(\boldsymbol{\bullet})$, Hcy $(\bullet)$ and $\mathrm{GSH}(\boldsymbol{\Delta})$, respectively. 
3. Biosensor 1 in response to the low Cys concentration:

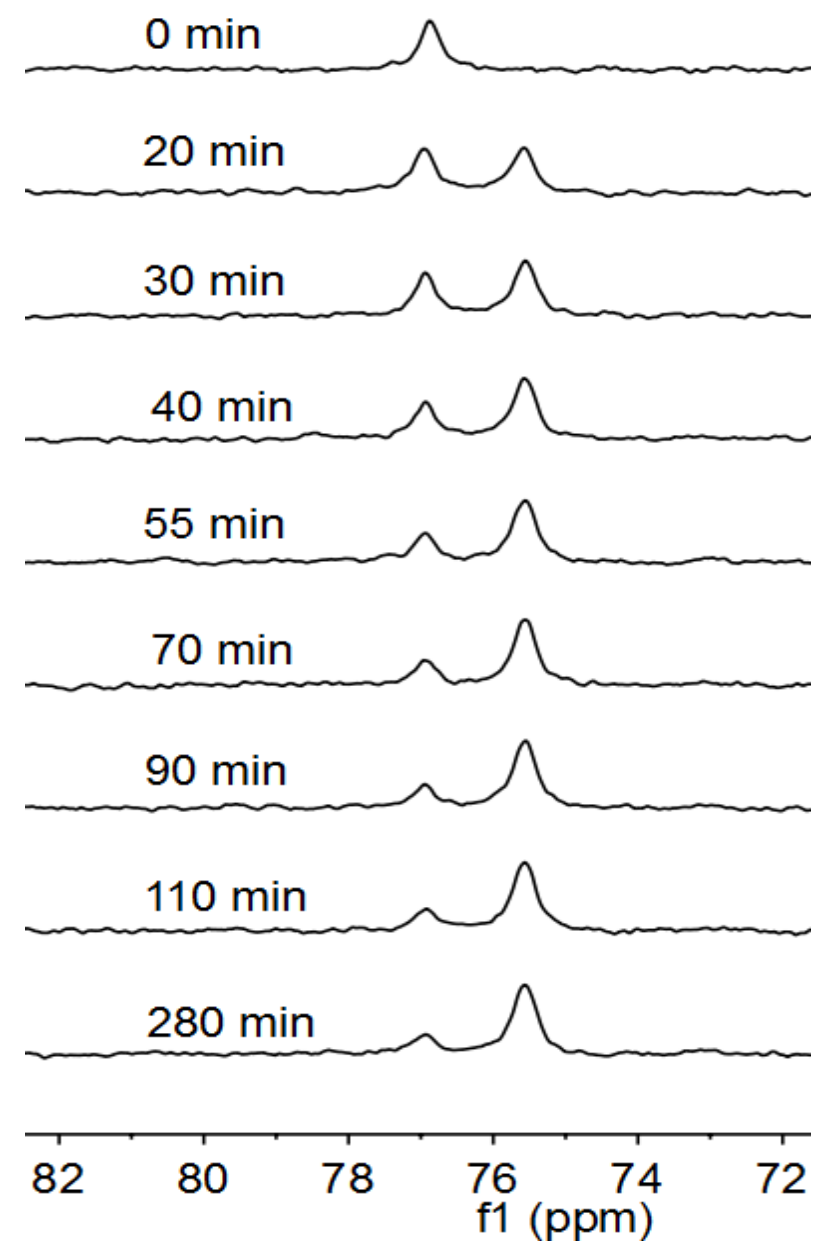

Figure S4. ${ }^{129} \mathrm{Xe}$ chemical shift change of cryptophane $1(200 \mu \mathrm{M})$ upon addition of 1 equiv Cys.

4. Biosensor 1 in response to Cys in HEPES buffer with $10 \%$ DMSO:

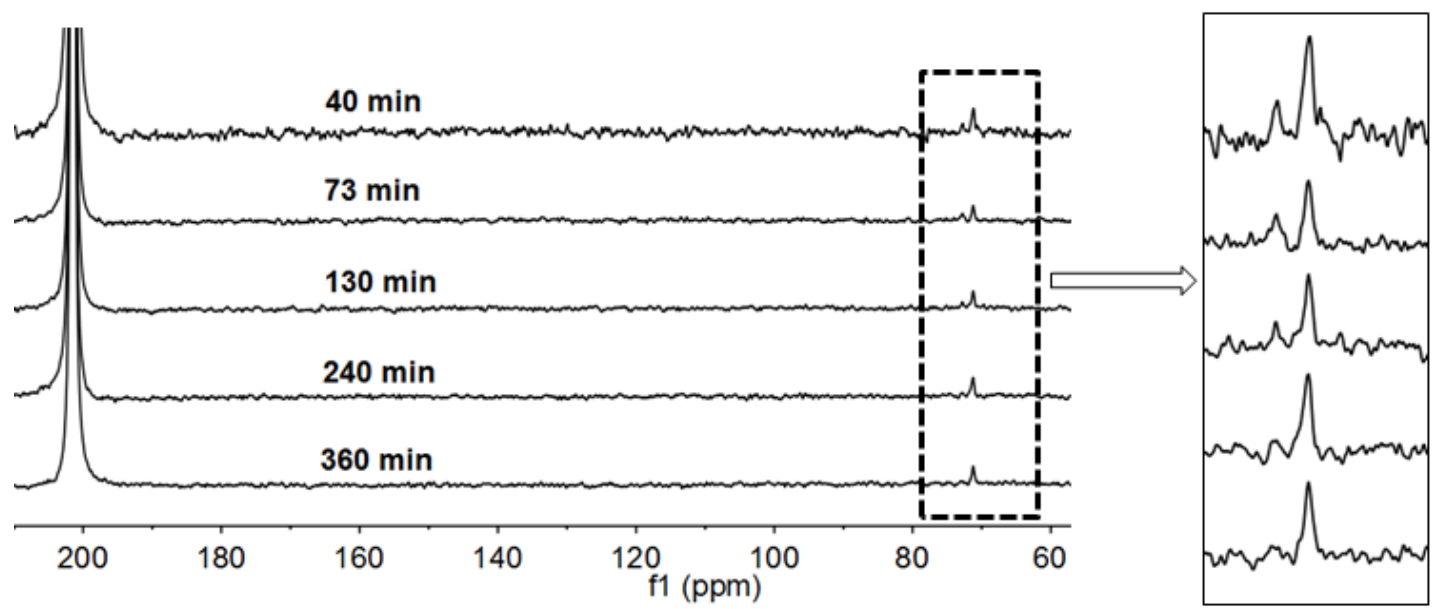

Figure S5. Time-dependent ${ }^{129} \mathrm{Xe}$ NMR spectra change of cryptophane $1(10 \mu \mathrm{M})$

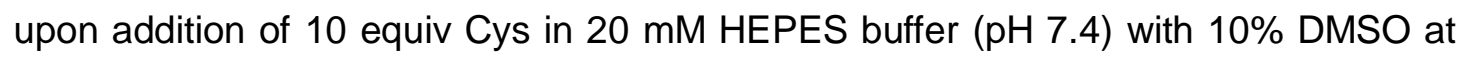


$25^{\circ} \mathrm{C}$. Under this conditions, the chemical shift of dissolved free Xe was at $\delta=201.4$ ppm and chemical shift of caged Xe in cryptophane 1 was at $\delta=72.8 \mathrm{ppm}$, respectively. After addition of 10 equiv Cys, a new signal at $71.2 \mathrm{ppm}$ appeared. The result means this reaction can proceed in low cryptophane concentration and DMSO content. All spectra were obtained with 32 scans.

\section{Absorption spectra of cryptophane 1 treated with 10 equiv of Cys:}

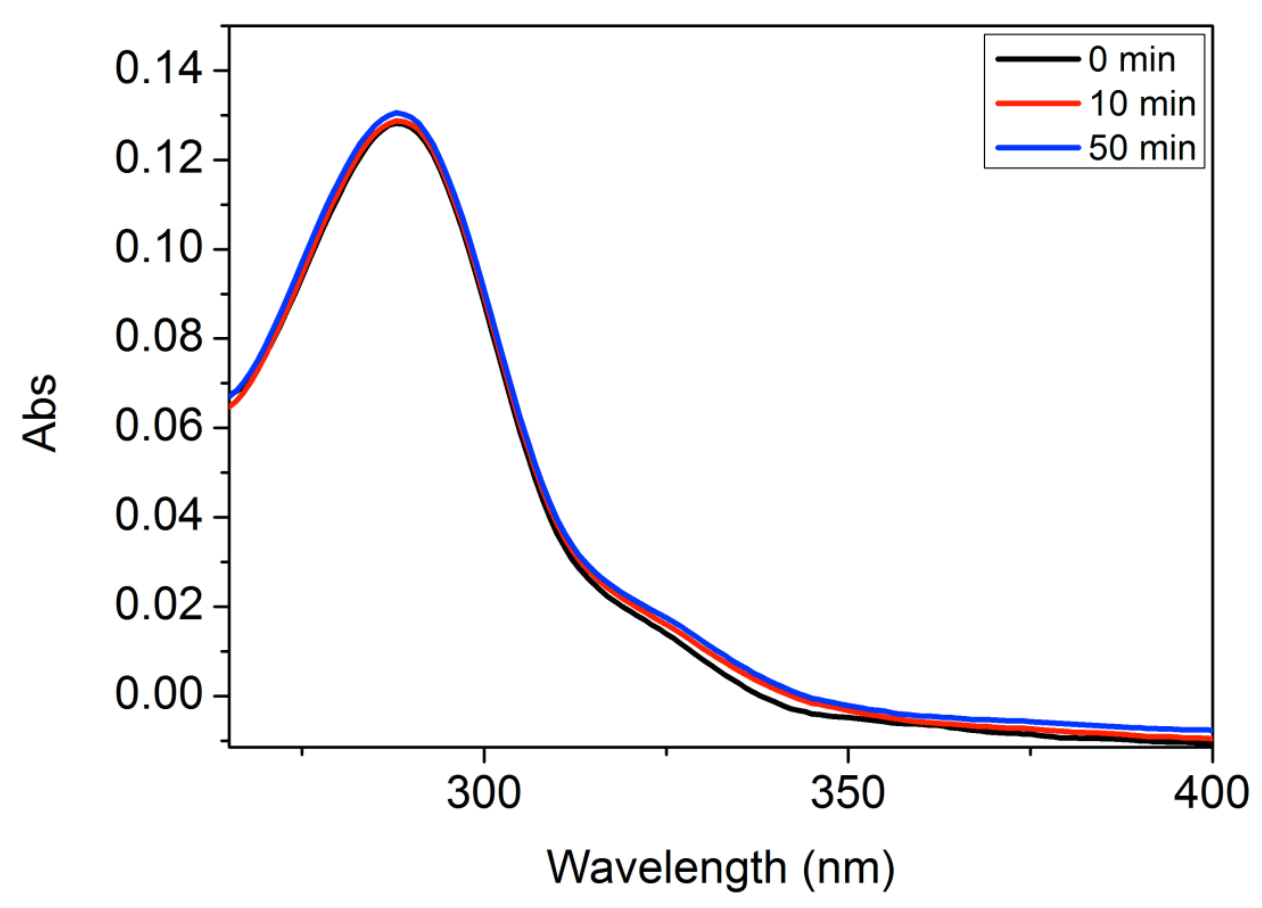

Figure S6. Absorption spectra of cryptophane $1(10 \mu \mathrm{M})$ after treated with 10 equiv Cys. The spectra were recorded at 0,10 and $50 \mathrm{~min}$. 
6. Biosensor 1 in response to Hcy:

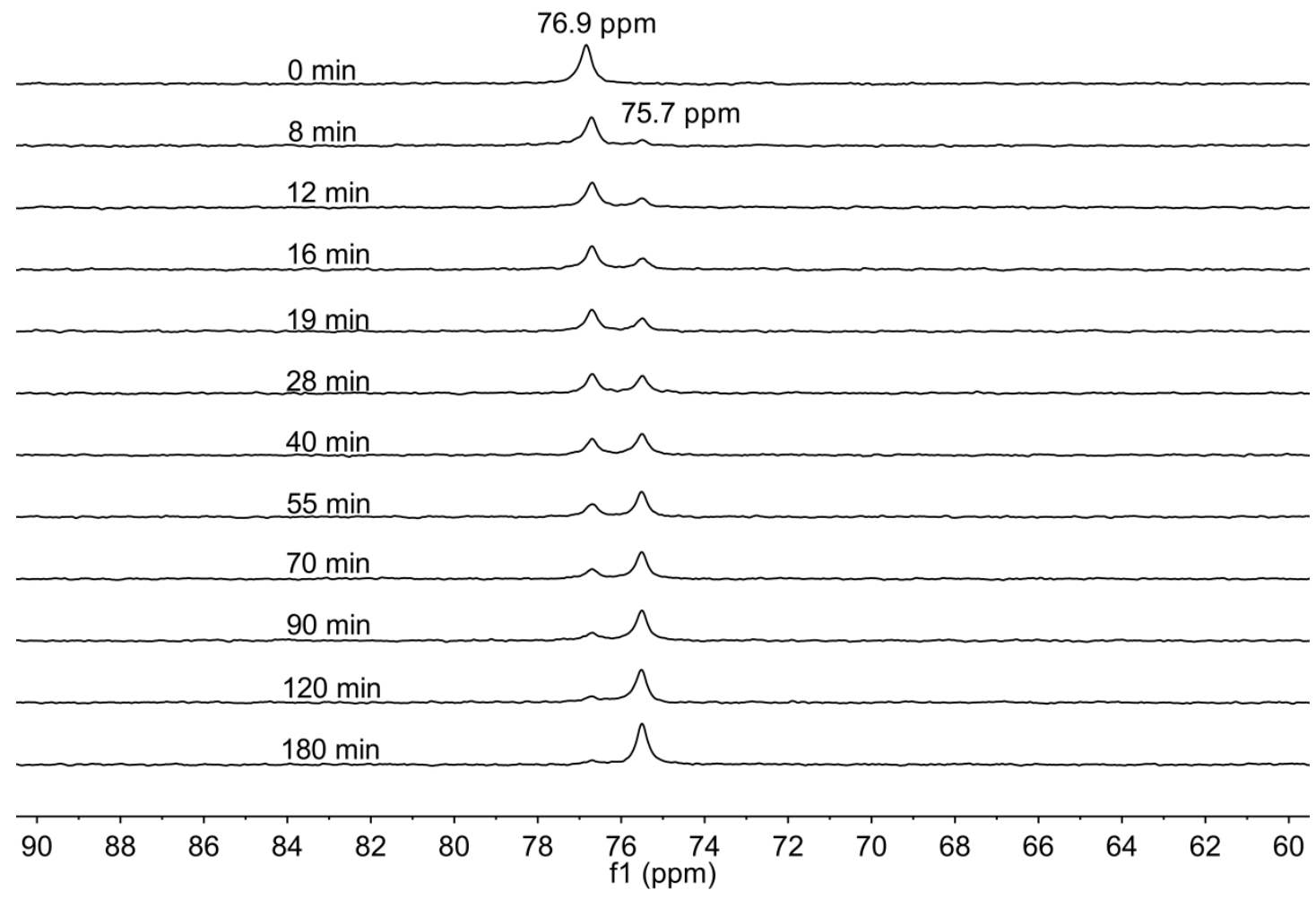

Figure S7. Time-dependent ${ }^{129} \mathrm{Xe}$ NMR spectra change of cryptophane $1(200 \mu \mathrm{M})$ upon addition of 3 equiv Hcy. All spectra were obtained with a single scan.

\section{Biosensor 1 in response to GSH:}

(16 min

Figure S8. Time-dependent ${ }^{129} \mathrm{Xe}$ NMR spectra change of cryptophane $1(200 \mu \mathrm{M})$ 
upon addition of 3 equiv GSH. All spectra were obtained with a single scan.

\section{TOF-MS spectrum of reaction product between cryptophane 1 and Cys:}

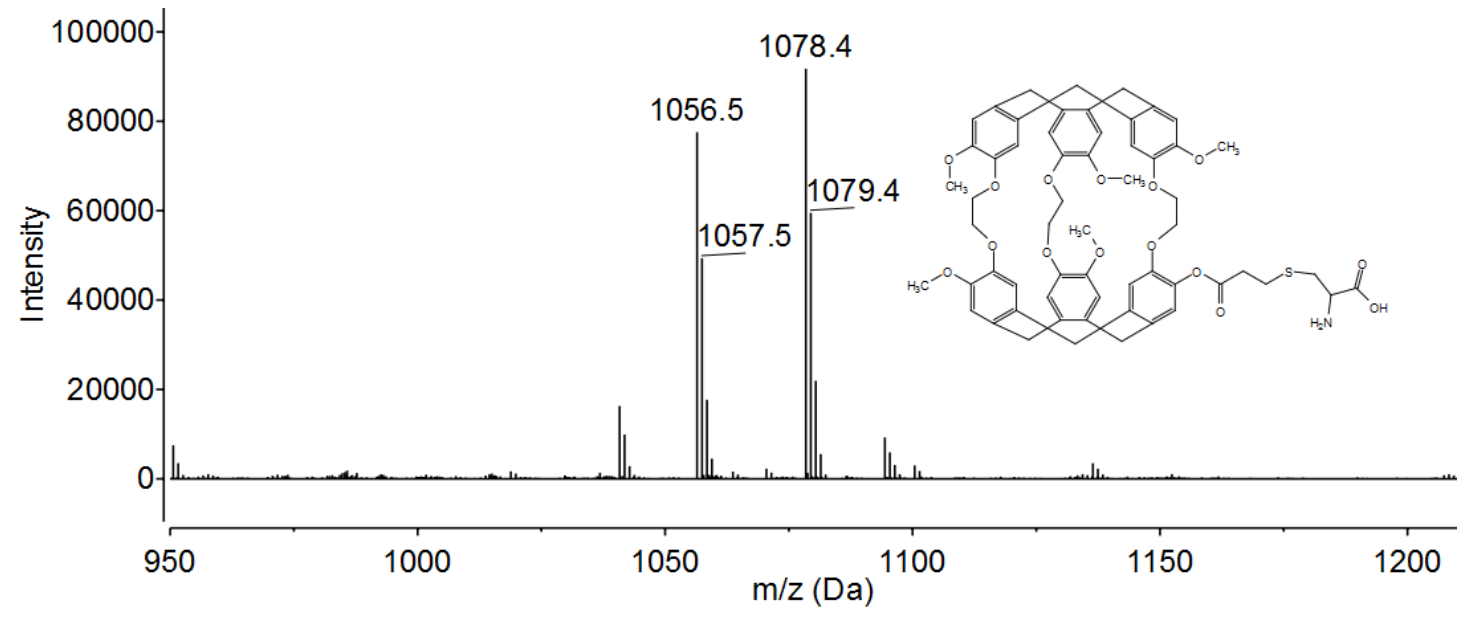

Figure S9. TOF-MS spectrum of reaction product between cryptophane 1 and Cys.

9. ${ }^{1} \mathrm{H}$ NMR spectral comparison between cryptophane 1 and [1-Cys] adduct:

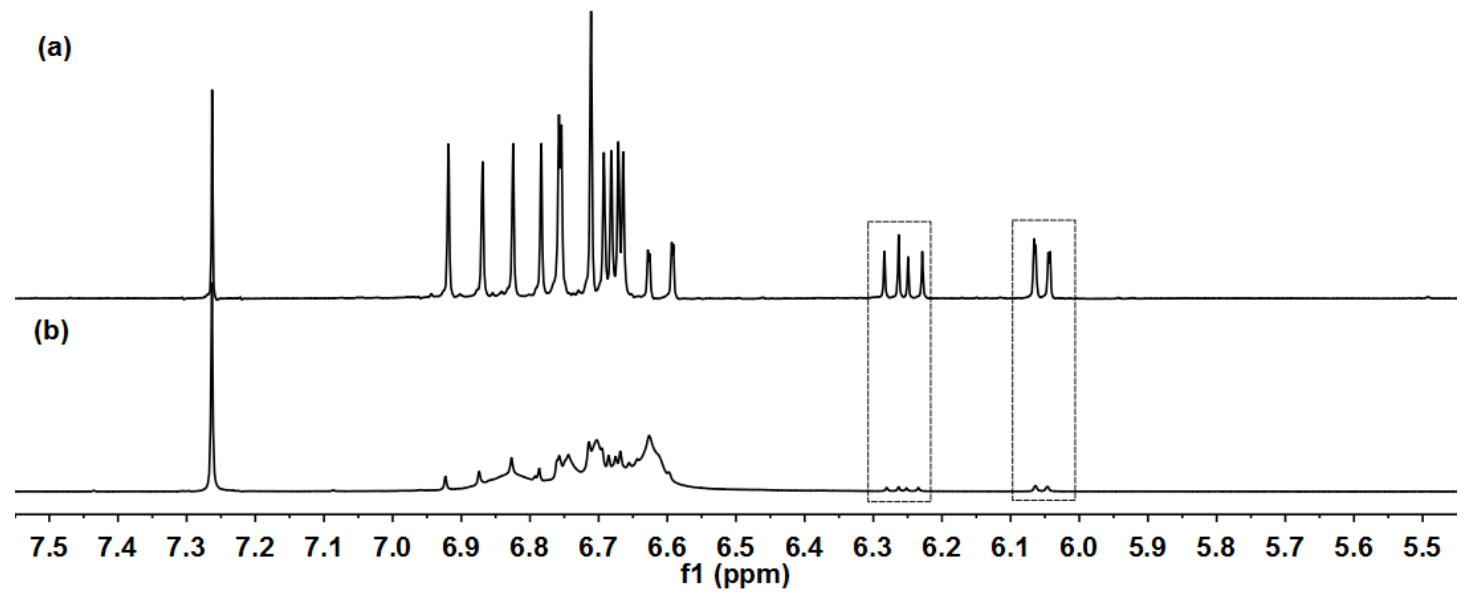

Figure S10. ${ }^{1} \mathrm{H}$ NMR spectral comparison between cryptophane 1 and its Cys adduct. (a) cryptophane 1 only; (b) [1-Cys] adduct. 
10. ${ }^{129} \mathrm{Xe}$ NMR chemical shift comparison of cryptophane 1 , cryptophane 2 and [1-Cys] adduct:

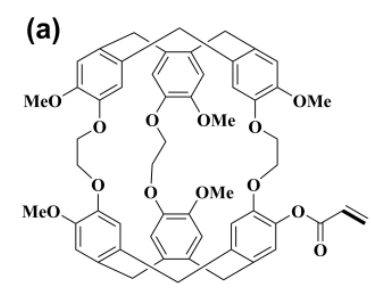

1

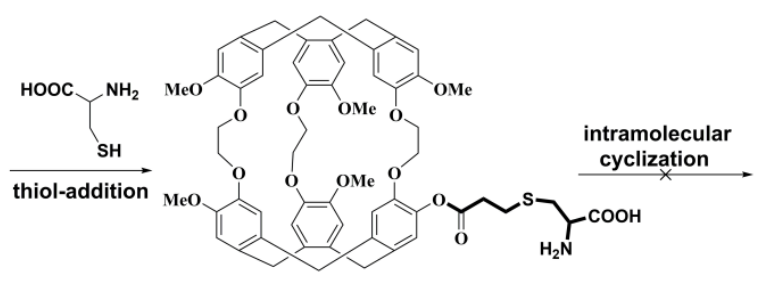

1-Cys

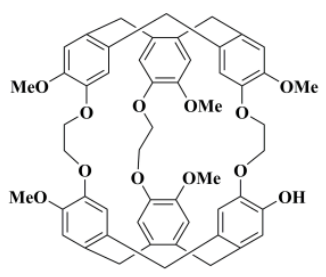

2

(b)

$76.9 \mathrm{ppm}$

1

$73.0 \mathrm{ppm}$

2

ᄉ

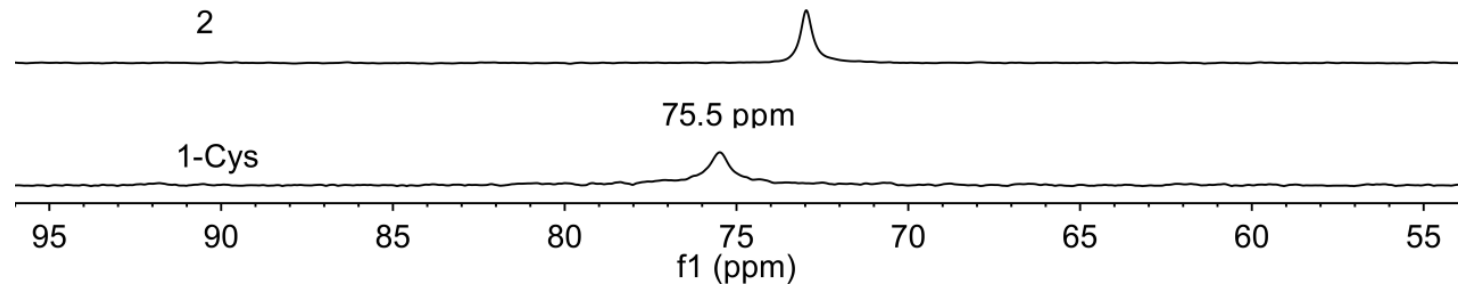

Figure S11. (a) The reaction of cryptophane 1 with Cys and (b) ${ }^{129}$ Xe NMR chemical shift of cryptophane 1, cryptophane 2 and [1-Cys] adduct. All spectra were obtained under the same test conditions. The result indicates that the reaction of cryptophane 1 with Cys do not undergo the intramolecular cyclization. 
11. ${ }^{129} \mathrm{Xe}$ spectra of cryptophane 1 in the presence of various analytes:

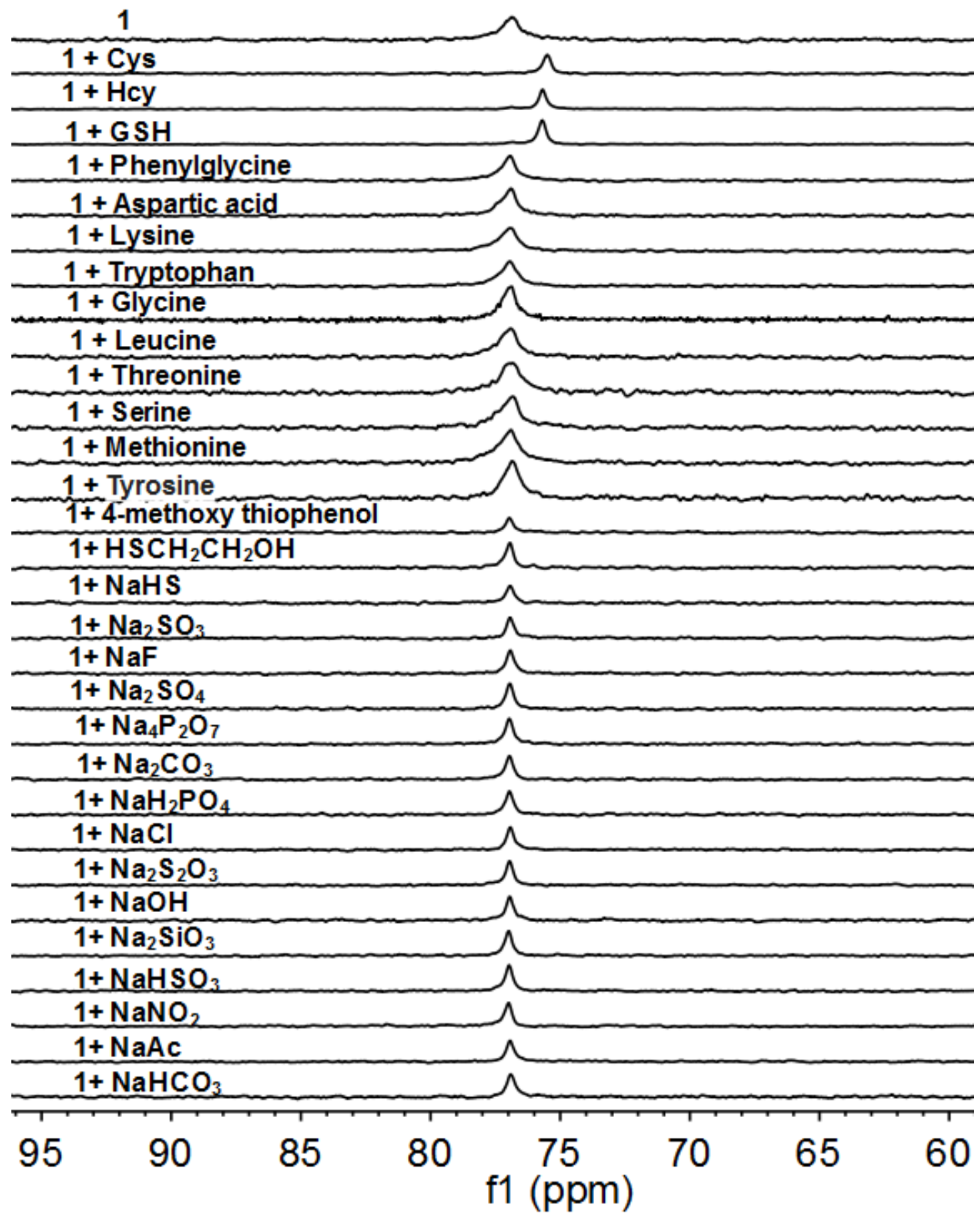

Figure S12. Single-scan ${ }^{129}$ Xe NMR spectra of caged xenon of cryptophane 1 (200 $\mu \mathrm{M}$ ) in the presence of various analytes (the concentration of Cys, Hcy and GSH were $600 \mu \mathrm{M}$, the rest analytes were $2000 \mu \mathrm{M})$. The result indicates that other analytes including amino acids and sulfur-containing molecular: 4-methoxy thiophenol, $\mathrm{HSCH}_{2} \mathrm{CH}_{2} \mathrm{OH}$, hydrogen sulfide, sulfite, sulfate, thiosulfate, and hydrogen sulfite caused no obvious ${ }^{129} \mathrm{Xe}$ NMR chemical shift change of cryptophane 1. 


\section{Sensitivity of biosensor 1 :}

(a)

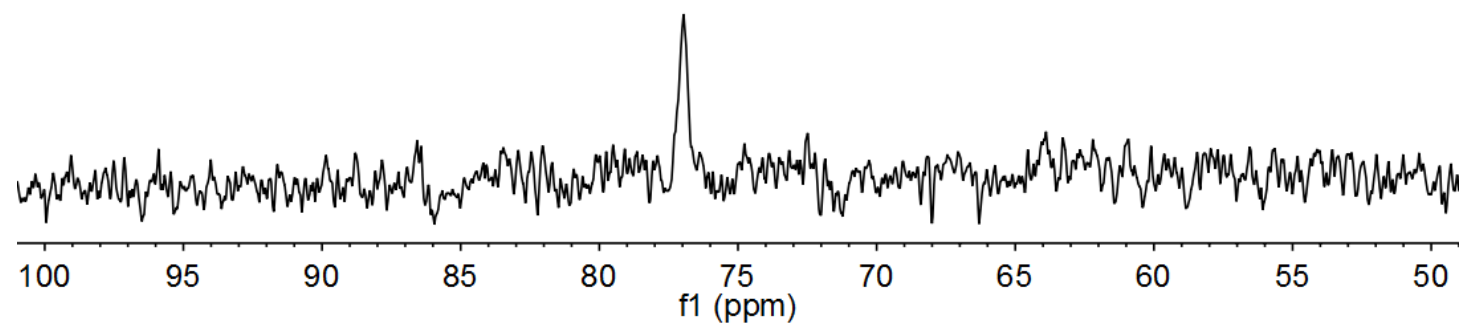

(b)

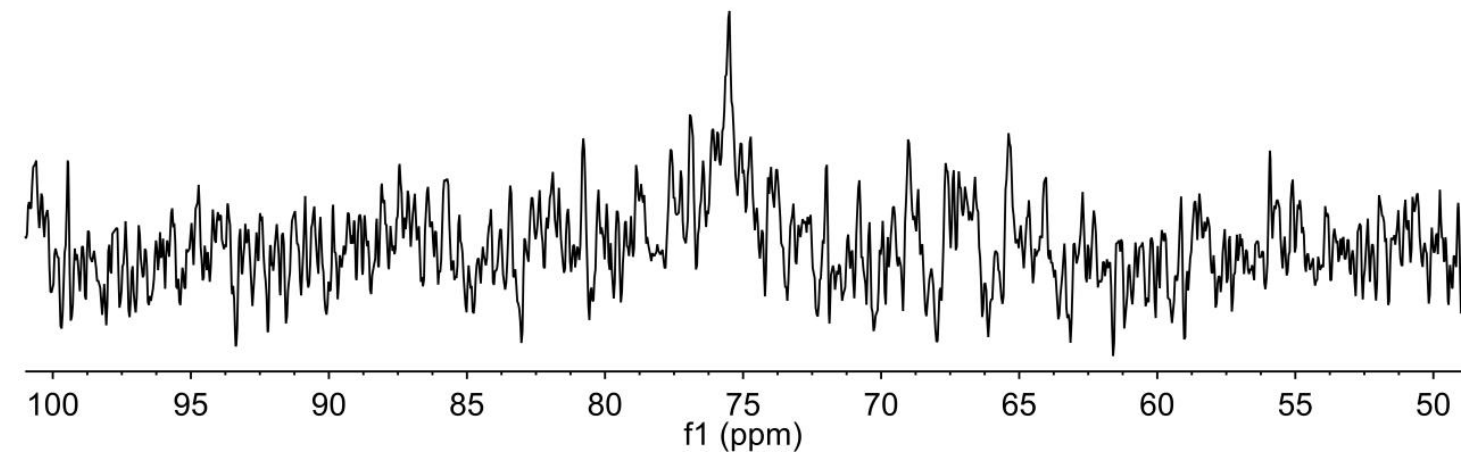

Figure S13. (a) Single scan ${ }^{129}$ Xe NMR spectrum of caged xenon of cryptophane 1 at a concentration of $10 \mu \mathrm{M}$. (b) 4096 signal averages enable the detection of ${ }^{129} \mathrm{Xe} N \mathrm{NR}$ of caged xenon of cryptophane 1 at a concentration of $80 \mathrm{nM}$ after treatment with Cys. In this experiment, Xe gas was introduced by continuous-flow at the rate of 0.08 standard liters per minute. 
13. Biosensor 1 in response to GSH and Hcy in bovine serum solution:

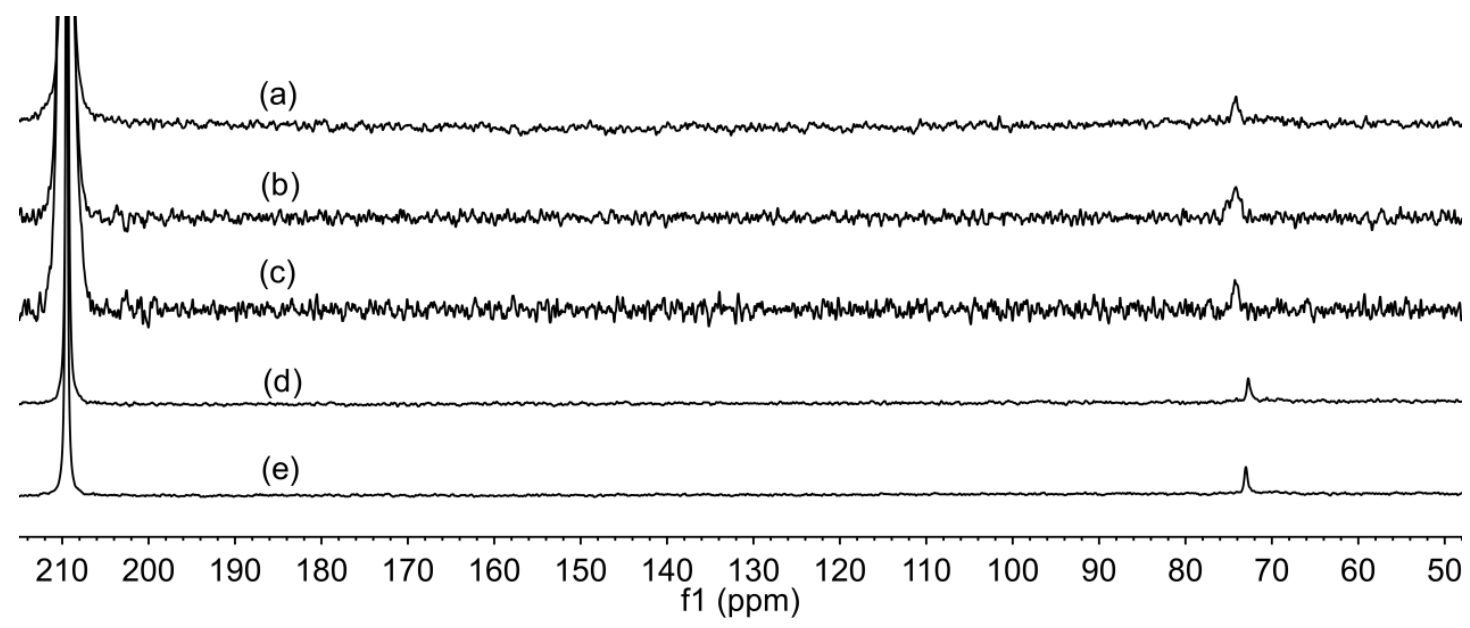

Figure S14. ${ }^{129} \mathrm{Xe}$ NMR spectra of cryptophane $1(40 \mu \mathrm{M})$ in $20 \mathrm{mM}$ HEPES buffer (pH 7.4) solution (containing $10 \%$ bovine serum and $20 \% \mathrm{DMSO}, \mathrm{v} / \mathrm{v}$ ) at (a) $10 \mathrm{~min}$, (b) 180 min, (c) $400 \mathrm{~min}$ and in the presence of (d) GSH, (e) Hcy. The ${ }^{129}$ Xe NMR chemical shift of caged xenon is (a) $74.1 \mathrm{ppm}$, (b) $74.1 \mathrm{ppm}$, (c) $74.1 \mathrm{ppm}$, (d) $73.0 \mathrm{ppm}$ and (e) $72.7 \mathrm{ppm}$, respectively. All spectra were obtained with 16 scans and the line width is $20 \mathrm{~Hz}$. 